\title{
Effect of Different Housing Systems on Growth Performance, Feed Consumption, Morbidity and Mortality of Broiler Rabbits
}

\author{
R.K. Prajapati ${ }^{1}$, H.D. Chauhan ${ }^{2}$, M.M. Pawar ${ }^{1}$, J.P. Gupta ${ }^{3}$, A.K. Srivastava ${ }^{1}$, \\ A.B. Paregi ${ }^{1}$, P.D. Patel ${ }^{1}$, J.V. Patel ${ }^{1}{ }^{*}$ and N.K. Thakkar ${ }^{1}$
}

${ }^{1}$ Department of Livestock Production and Management, ${ }^{2}$ Department of Animal Nutrition,

${ }^{3}$ Department of Animal Genetics and Breeding, College of Veterinary Science and Animal Husbandry, Sardarkrushinagar Dantiwada Agricultural University, Sardarkrushinagar, India

*Corresponding author

\section{Keywords}

Rabbit, Housing, Growth, Feed Intake, Mortality

Article Info

Accepted:

18 February 2019

Available Online:

10 March 2019

\section{A B S T R A C T}

The present investigation was conducted to study the effects of different housing systems on growth performance, feed consumption, morbidity and mortality of broiler rabbits in semi arid region of North Gujarat. Total 24 weaned rabbits (28 days age) were randomly divided in two housing treatments, $\mathrm{T}_{1}$ (Cage housing) and $\mathrm{T}_{2}$ (Deep litter housing system). The duration of experiment was 8 weeks. Dimensions of cage were $3 \times 2 \times 2$ feet $(3$ rabbits/cage) whereas, in deep litter, 12 rabbits were kept in 24 square feet area ( 2 square feet/rabbit). Animals were fed restricted amount of concentrate and vegetables whereas green fodder was fed $a d$-lib. Weighted quantity of feed were given to rabbits and left over was collected next day early morning before offering fresh feed. Weekly observations were recorded for weekly body weight, weight gain and daily feed consumption data generated were analyzed for significant differences. Initial average body weight was $0.739 \pm 0.05 \mathrm{Kg}$ and $0.736 \pm 0.07 \mathrm{Kg}$, respectively, in $\mathrm{T}_{1}$ and $\mathrm{T}_{2}$ groups. At the end of experimental period $\left(12^{\text {th }}\right.$ week of age), there was no significant difference in the final body weight $\left(2.619 \pm 0.09 \mathrm{~kg} \mathrm{v} / \mathrm{s} 2.500 \pm 0.10 \mathrm{~kg}\right.$ ) between $\mathrm{T}_{1}$ and $\mathrm{T}_{2}$ groups. Average weekly body weight gain was marginally high (but non-significant) in $T_{1}(0.234 \pm 0.02 \mathrm{~kg})$ than $\mathrm{T}_{2}(0.220 \pm 0.01 \mathrm{~kg})$. There was no apparent morbidity and mortality in rabbits during the experimental period. The results indicate that weight gain were at par in the cage and deep litter system of housing. Further, maintaining well hygienic condition in deep litter system and changing the litter materials at the regular interval; gives the similar results as in cage system.

\section{Introduction}

Rabbit belong to the order lagomorpha, which has two families (leporidae and ochotonidae) that comprise 12 genera. The modern rabbit is
Oryctolagus cuniculus, a descendant of the european wild rabbit. The rapid growth of human population and improvement in per capita consumption continue to widen the gap between the demand and supply of meat. This 
gap can be bridged only by increasing meat production from different livestock species through improving their genetic makeup together with improved managerial practices. The rabbit population is 0.59 million in India, and is considered as livestock for the first time during 2003 in a livestock censes but domestication of rabbits since last 1972 (Anonymous, 2016). There are two conventional housing methods in rabbit rearing, rabbits are either kept in cages without (or with) bedding or group housed and Wire cage housing for rabbits is considered most economical and is more widespread (Morton et al., 1993), although each housing method has its advantages and disadvantages. When cage keeping without bedding is applied, rabbit excrements falls through the bars without heaping, so the risk of coccidiosis is reduced.

When kept on straw bedding, rabbits have a warmer lying area, there is a lower influence of outside temperatures, yet constant contact with the manure increases the risk of coccidiosis. In recent years, consumer's interest in specially products derived from free-range or organic production system has steadily increased in Europe and other parts of the world. Generally, extensive housing systems provide animals with more space and freedom of movement to animals, which permit a broad range of behavior patterns and better satisfy the natural and social needs of rabbits (Morisse et al., 1999). One of the solutions to the problem is changing of the cage design by making all or part of the cages higher. Housing systems should be efficient in environmental thermoregulation to insure better rearing through good biological performance, thus high economic return. Housing for livestock is designed to suit the prevailing climatic conditions, bearing in mind the availability and cost of materials and local construction workers skills when thermal stress would negatively influence animal welfare and productivity.

\section{Materials and Methods}

The study was conducted at Rabbit Unit, Instructional Livestock Farm Complex, Department of Livestock Production and Management, College of Veterinary Science and Animal Husbandry, Sardarkrushinagar Dantiwada Agricultural University, Sardarkrushinagar. All the experimental rabbits were reared with does till $4^{\text {th }}$ week of age and after that weaning were done and they were distributed randomly into 2 treatment groups as per the technical plan of investigation. The treatment groups were made by keeping rabbits in cage and deep litter. In one cage of $3 \times 2 \times 2$ feet, maximum 3 experimental rabbits were kept. Door of the cage was rear side of cage and cage was kept 2 feet high on the metal stand from the floor. In Deep litter house the wall was prepared by red bricks and height was 2.5 feet: deep litter material of wheat straw was spread of $5 \mathrm{~cm}$ thickness. Floor of deep litter housing was made using Kota stone. In deep litter system 2 square feet floor space (minimum) was provided to each rabbit. All the rabbits were weighed individually with electronic weighing balance in morning before offering feed and water and that was taken as initial body weight of rabbits.

All possible measures were strictly followed to maintain standard and uniform managemental conditions to all the experimental rabbits throughout the experimental period. Room temperature was almost in the range of $18-25^{\circ} \mathrm{C}$ throughout the experimental period. Experimental rabbits were offered, measured amount of concentrate and fresh vegetables, while green fodder and clean and fresh drinking water was provided adlibitum to all experimental rabbits. The water bowls were being washed daily and then filled with cool fresh water frequently as to avoid the heat stress. The rabbits were protected against various diseases by taking 
strict sanitary measures and routine cleaning and washing of feeding and watering utensils. Faecal samples were examined at monthly interval (at $8^{\text {th }}$ and $12^{\text {th }}$ week of age) for parasitic infection (coccidial oocyst) in the department of veterinary parasitology using sedimentation method for diagnosis of parasitic eggs. The data were analyzed using standard statistical procedures for mean comparison of differences between treatment groups by T-test as described by Snedecor and Cochran (1994).

\section{Results and Discussion}

The growth performance indices of the weaned rabbits raised under the two different housing systems are presented in Table 1 and 2 and feed consumption were showed in Table 3. During the 11th and 12thweek of age fighting between animal was accrued and animal was injured so that two rabbits of cage housing system were excluded from experiment for two weeks. Data of two animals was not included in last two weeks. The result showed that no significant $(\mathrm{P}<$ 0.05) different in the weekly body weight, body weight gain and feed consumption.

\section{Weekly body weight (Kg)}

The mean of twelfth week body weight (Final body weight) was found to be $2.619 \pm 0.09$ and $2.500 \pm 0.10 \mathrm{~kg}$ in cage housing system and deep litter housing system respectively. Overall, result showed the body weight of rabbits during 12th week of age was at par in both the housing systems. Body weight in cage housing system $\left(2.619 \pm 0.09 \mathrm{~kg}, \mathrm{~T}_{1}\right)$ and $\left(2.500 \pm 0.10 \mathrm{~kg}, \mathrm{~T}_{2}\right)$ had no significant difference. The findings was in agreement with the findings of Verga et al., (2004) they found no significant difference in live weight from simple cage and wood stick hanging from the ceiling of the cage. Trocino et al., (2008) notice that the rabbits kept on straw bedded floor showed the lowest final weight as compared to plastic slat or wire net floors but housing was not significantly affected. Stewart and Suckow (2016) observed no significant differences in body weight between groups housed in cages with different heights and amounts of floor space.

Laxmi et al., (2009) found fryers reared in backyard weighed heavier than those kept in cages, although the difference was statistically not significant and Zoltan et al., (2008) reported that housing system had no significant effect on body weight. Overall result was non significant on the body weight due to different housing system because of the uniformity in feeding and watering as well as environmental conditions.

The findings was in contrast with the earlier reporters; Shivkumar et al., (1991), Lazzaroni et al., (2009), Pinheiro et al., (2011), Xiccato et al., (2013 $)$, Matics et al., (2014), Maha et al., (2015), Chandra et al., (2014), Nevalainen et al., (2007), Robert and codrin. (2009), Shehu and Mahmoud.(2013), Maertens and Van. (2000) they found significant effect of housing on body weight.

\section{Body weight gain (Kg)}

The mean weekly body weight gains (Kg) along with standard errors for all the weeks are presented in Table 2. At the end of 4th week (weaning) body weight of 24 rabbits were taken and average of it was recorded to be $0.740 \pm 0.062 \mathrm{~kg}$. The mean for body weight gain during whole experimental period $\left(\mathrm{BWG}_{5-12}\right)$ was found to be the highest in cage housing system $(0.234 \pm 0.024 \mathrm{~kg})$ followed by deep litter housing system $(0.220 \pm 0.017$ $\mathrm{kg}$ ). The results revealed that body weight gain of rabbits during $12^{\text {th }}$ week of age was higher in cage system as compare to deep litter housing system. Mean Body weight gain in cage housing system $(0.234 \pm 0.024 \mathrm{~kg})$ and 
deep litter housing system $(0.220 \pm 0.017 \mathrm{~kg})$ had no significant difference. The findings were in agreement with the reports of earlier workers. Stewart and Suckow (2016) observed no significant differences in body weight gain between groups housed in cages with different heights and amounts of floor space. Laxmi et al., (2009) found that at the age of 4, 8, and 10 weeks, the fryers reared in backyard weight gain higher than those kept in cages, although the difference was statistically not significant, Zoltan et al., (2008) reported that the average daily weight gain at the age of 5 th and 11 th weeks was not differ due to cage height.

Overall they reported that body weight gain was not affected by different housing systems. The findings were in contrast with the reports of earlier workers Shivkumar et al., (1991), Bosco et al., (2002), Verga et al., (2004), Trocino et al., (2008), Villalobos et al., (2008), Lazzaroni et al., (2009), Pinheiro et al., (2011), Xiccato et al., (2013 $)$, Matics et al., (2014), Maha et al., (2015), Chandra et al., (2014), Nevalainen et al., (2007), Robert and codrin (2009), Shehu and Mahmoud.(2013), Maertens and Van. (2000), Princz et al., (2008), Metzger et al (2003) who reported that the housing systems had significant $(\mathrm{p}<0.05)$ effect on the body weight gain. In the study no morbidity and mortality was observed in any group. During the $11^{\text {th }}$ and $12^{\text {th }}$ week of age fighting between animal was accrued and animal was injured so that two rabbits of cage housing system were excluded from experiment for two weeks. These finding are in agreement with earliest studies of Zoltan et al., (2008), reported that housing systems has no effect on morbidity during the 8 week duration but increases at age 11 and 12 week in rabbits. Similarly, Paci et al., (2008) reported that only T16 (16 animal/cage) group have higher aggressiveness compared to T8 (8 animal/cage) group.

Overall, the results revealed that feed consumption (g/rabbit/week) for all the weeks was remain higher in cage housing group $\left(T_{1}\right)$ compared to deep litter housing group deep litter housing system. The average feed consumption (g/rabbit/week) during experimental period (5- $12^{\text {th }}$ week) was 807.9 \pm 64.99 and $809.1 \pm 65.40 \mathrm{~g}$ in cage housing system and deep litter housing system respectively. Statistical analysis showed that there was no significant difference in feed intake due to different housing systems.

Table.1 Average weekly body weight $(\mathrm{kg})$ of broiler rabbits at different age

\begin{tabular}{|c|c|c|}
\hline Age in weeks & $\begin{array}{c}\text { Cage housing system } \\
(\mathbf{n}=\mathbf{1 2})\end{array}$ & $\begin{array}{c}\text { Deep litter housing system } \\
(\mathbf{n = 1 2})\end{array}$ \\
\hline $\mathbf{4}$ & $0.739 \pm 0.054$ & $0.736 \pm 0.075$ \\
\hline $\mathbf{5}$ & $0.997 \pm 0.059$ & $0.977 \pm 0.081$ \\
\hline $\mathbf{6}$ & $1.283 \pm 0.063$ & $1.250 \pm 0.082$ \\
\hline $\mathbf{7}$ & $1.520 \pm 0.064$ & $1.494 \pm 0.079$ \\
\hline $\mathbf{8}$ & $1.826 \pm 0.077$ & $1.754 \pm 0.087$ \\
\hline $\mathbf{9}$ & $2.072 \pm 0.075$ & $1.976 \pm 0.082$ \\
\hline $\mathbf{1 0}$ & $2.275 \pm 0.085$ & $2.197 \pm 0.091$ \\
\hline $\mathbf{1 1}$ & $2.389 \pm 0.065$ & $2.360 \pm 0.101$ \\
\hline $\mathbf{1 2}$ & $2.536 \pm 0.093$ & $2.500 \pm 0.106$ \\
\hline Overall & $\mathbf{2 . 3 4 4} \pm \mathbf{0 . 1 8 9} \mathbf{N S}$ & $\mathbf{2 . 4 2 9} \pm \mathbf{0 . 1 8 2} \mathbf{~ N S}$ \\
\hline
\end{tabular}

All the average weekly body weights, under different housing systems do not differ significantly $(\mathrm{p} \leq 0.05)$. 
Table.2 Average weekly body weight gain of broiler rabbits at different age

\begin{tabular}{|c|c|c|}
\hline Age in weeks & $\begin{array}{c}\text { Cage housing system } \\
(\mathbf{n = 1 2})\end{array}$ & $\begin{array}{c}\text { Deep litter housing system } \\
(\mathbf{n = 1 2})\end{array}$ \\
\hline $\mathbf{4 - 5}$ & $0.258 \pm 0.010$ & $0.241 \pm 0.012$ \\
\hline $\mathbf{5 - 6}$ & $0.286 \pm 0.012$ & $0.273 \pm 0.009$ \\
\hline $\mathbf{6 - 7}$ & $0.236 \pm 0.013$ & $0.244 \pm 0.021$ \\
\hline $\mathbf{7 - 8}$ & $0.305 \pm 0.025$ & $0.259 \pm 0.021$ \\
\hline $\mathbf{8 - 9}$ & $0.246 \pm 0.011$ & $0.221 \pm 0.013$ \\
\hline $\mathbf{9 - 1 0}$ & $0.202 \pm 0.013$ & $0.220 \pm 0.014$ \\
\hline $\mathbf{1 0 - 1 1}$ & $0.114 \pm 0.021$ & $0.163 \pm 0.012$ \\
\hline $\mathbf{1 1 - 1 2}$ & $0.146 \pm 0.024$ & $0.139 \pm 0.017$ \\
\hline Overall & $\mathbf{0 . 2 2 5} \pm \mathbf{0 . 0 2 4} \mathbf{N S}$ & $\mathbf{0 . 2 2 0} \pm \mathbf{0 . 0 1 7} \mathbf{~ N S}$ \\
\hline
\end{tabular}

All the average weekly body weight gains, under different housing systems did not differ significantly $(\mathrm{p} \leq 0.05)$.

Table.3 Average DM consumption (g/rabbit/week) of broiler rabbit at different age

\begin{tabular}{|c|c|c|}
\hline Age in weeks & $\begin{array}{c}\text { Cage housing system } \\
\left.\mathbf{( T}_{\mathbf{1}}\right)\end{array}$ & $\begin{array}{c}\text { Deep litter housing system } \\
\left(\mathbf{T}_{\mathbf{2}}\right)\end{array}$ \\
\hline $\mathbf{4 - 5}$ & 457.34 & 444.99 \\
\hline $\mathbf{5 - 6}$ & 683.41 & 643.17 \\
\hline $\mathbf{6 - 7}$ & 799.01 & 768.13 \\
\hline $\mathbf{7 - 8}$ & 863.96 & 833.56 \\
\hline $\mathbf{8 - 9}$ & 923.24 & 907.11 \\
\hline $\mathbf{9 - 1 0}$ & 938.35 & 942.40 \\
\hline $\mathbf{1 0 - 1 1}$ & 975.27 & 970.91 \\
\hline $\mathbf{1 1 - 1 2}$ & 979.83 & 962.52 \\
\hline Overall & $\mathbf{8 3 4 . 4} \pm \mathbf{6 4 . 9 9} \mathbf{N S}$ & $\mathbf{8 0 9 . 1} \mathbf{6 5 . 4 0} \mathbf{~ N S}$ \\
\hline
\end{tabular}

DM consumption, under different housing systems did not differ significantly.

The result of present study is supported by the findings of Zoltan et al., (2008) found that the cage height did not affect significantly on the weekly or the total feed consumption. Baiomy (2012) report that cage density did not affect feed efficiency. Supporters of present findings reported housing systems had no effect on feed consumption.

However, in contrast to the present findings Whary, et al., (1993), Maertens and van (2000), Lambertini et al., (2001), Bosco et al., (2002), Trocino et al., (2008), Owen et al., (2008), Lazzaroni et al., (2009), Pinheiro et al., (2011), Robert and codrin (2009), Shehu and Mahmoud (2013), Xiccato et al., (2013 $\left.{ }^{\mathrm{b}}\right)$, Matics et al., (2014), reported significant difference $(\mathrm{p}<0.05)$ in DMI due to different housing systems.

The feed consumption was found at par in both the housing systems at age of the $12^{\text {th }}$ weeks might be due to the provision of ad.libitum feeding in both the groups.

In conclusion,

Specially in term of growth performance both the housing systems was acceptable but outdoor (deep litter) rearing system may be 
considered favorable alternative housing system because it satisfy the specific requirement of rabbits and also allay the ethical concern of modern consumers: the better sanitary conditions, greater space available and both quality and variability of environment stimuli improved animal welfare. In cage housing fighting between animal was observed but no mortality and morbidity was observed in any group.

The overall feed consumption was higher in cage housing system.

In cage housing, fighting between animals was observed but no mortality and morbidity was observed in any group.

\section{References}

Anonymous 2016. Basic Animal Husbandry Statistics. Department of Animal Husbandry, Dairying and Fisheries. Ministry of Agriculture, Government of India. Krishi Bhavan, New Delhi.

Bosco. A. D., Castellini C. and Mugna, C. 2002. Rearing rabbits on a wire net floor or straw litter: behaviour, growth and meat qualitative traits. Livestock Production Science.75: 149-156.

Baiomy. A. A. 2012. Growth and carcass traits of New Zealand white rabbits reared in Upper Egypt as affected by cage density. Egyptian Poultry Science. 32(3): 475-481.

Chandra S., Mahender M., Prakash, M. G., Raghunandan, T. and Reddy K. K. 2014. Productive performance of broiler rabbits fed diets supplemented with probiotic and enzymes under two systems of housing. Indian Journal of Animal Research. 48(4): 355-361.

Laxmi P. J. Gupta, B. R., Gnana, P. M., Ekambaram B. and Amareswari P. 2009. A study on the performance of fryer rabbits under different systems of rearing. Livestock Research for Rural Development. 21(8).140-145.
Lazzaroni C., Biagini, D. and Lussiana C. 2009. Different rearing systems for fattening rabbits: performance and carcass characteristics. Meat Science. 82: 200204.

Lambertini, L., Vignola, G. and Zaghini, g. 2001. Alternative pen housing system for fattening rabbits: effect of group density and litter. World Rabbit Science. 9 (4): 141-147.

Maertens L. and Van H. A. 2000. Performances of weaned rabbits raised in pens or in classical cages: first results. In Proceedings of the $7^{\text {th }}$ world rabbit congress. 4-7 July 2000 - Valencia Spain. pp: 335- 440.

Maha S., Wael. A. M., Radi. A. M., Mohamed. M. E., Sami A. and Midany. E. 1. 2015.Effect of weaning age and housing model on feed intake, growth performance, hemato-biochemical parameters and economic efficiency of post weaning New Zealand White rabbits. Alexandria Journal of Veterinary Sciences. 46: 48-56.

Matics. Z., Szendro. Z., Odermatt. M., Gerencsér. Z., Nagy, I., Radnai. I. and Dalle Z. 2014. Effect of housing conditions on production, carcass and meat quality traits of growing rabbits. Meat Science.96: 41-46.

Metzger S., Kustos, K., Szendro, Z.,Szab, A., Eiben, C. and Nagy, I. 2003. Effect of alternative housing on carcass traits of rabbits. Agriculturae Conspectus Scientificus. 68(3): 151-154.

Morisse, J. P., Boilletot, E. and Martrenchar, A. 1999. Preference testing in intensively kept meat production rabbits for straw on wire grid floor. Applied Animal Science. 64: 71-80.

Morton D. B., Jennings, M. and Batchelor, G. R. 1993.Refinements in rabbit husbandry. Second report of the BVAAWF/FRAME/RSPCA/UFAW joint working group on refinement. Laboratory Animal.27: 301-329.

Nevalainen T.O., Nevalainen J. I., Guhad F.A. and Lang C.M. 2007. Pair housing of rabbits reduces variances in growth rates 
and serum alkaline phosphatase levels. Laboratory Animals. 41. PP: 432-440.

Owen O. J., Chukuigwe, E. C., Amakiri A. O. and Aniebo. A. O. 2008. Bamboo hutches as a replacement for wire mesh cages in rabbit production in Nigeria. Livestock Research for Rural Development. 20 (11): $1-6$.

Paci, G., Mozzoni, C., Preziuso, G., Agata, M. and Russo, C. 2008. Outdoor rearing system for fattening rabbits: effect of group size. 9th World Rabbit Congress Verona - Italy. June, 10-13, 2008.

Pinheiro V., Divanildo M. O., Silva, S., Silva. J. and Jouse. L. M. 2011. Growth performance, carcass characteristics and meat quality of growing rabbits housed in cages or open-air park. Archivtierzucht. 54(6): 625-635.

Princz, Z., Radnai, I., Biro-Nemeth, E., Matics Z., Gerencser Z., Nagy I. and Szendro Z. 2008. Effect of cage height on the welfare of growing rabbits. Applied Animal Behaviour Science. 114: 284-295

Robert, C. and Codrin, G. 2009. Effect of cage floor and stocking density on growth performance and wellbeing of group housed rabbit. Facicula ecotoxicology. 8:259-264.

Shehu B. M. and Mohmoud M.M. 2013. Performance of weaned rabbits raised in cages or pens in Northern Guinea Savannah zone of Nigeria. Animal Production.15(3). pp: 180-182.

Shivkumar, T., Sundaram.S., Vishvanathan. R. and Sanmungam, A. 1991. The growth performance of broiler rabbits raised in cage vis-à-vis litter floor. Indian Journal of Animal Production Management. 7(3): 162-165.

Snedecor G. W. and Cochran. W. G. 1994.
Statistical methods. $8^{\text {th }}$ edition. Oxford and IBH Publishing Corporation. New Delhi.

Stewart K.L. and Suckow, M.A. 2016. Effects of nominal differences in cage height and floor space on the wellbeing of rabbits. Journal of the American Association for Laboratory Animal Science.55 (2): 168171.

Trocino, A., Xiccato, G., Majolini, D. and Fragkiadakis, M. 2008. Effect of cage floor and stocking density on growth performance and welfare of group-housed rabbits. Ethology and Welfare.5: 12511256.

Verga M., Zingarelli I., Heinzi, E., Ferrante V., Martino P. A. and Luzi F. 2004. Effect of housing and environmental enrichment on performance and behaviour in fattening rabbits. Sezione di Microbiologiae Immunologia. 10: 1283-1288.

Villalobos O., Guillen, O. and Garcia, J. 2008. Effect of cage density on growth and carcass performance of fattening rabbits under tropical heat stress conditions. World Rabbit Science.16: 89-97.

Whary M., Randall P., Gary B., Wendy L. and Frederick, F. 1993. The effects of group housing on the research use of the laboratory rabbit. Laboratory Animals. 27: 330-341.

Xiccato G., Trocino A., Majolini, D., Tazzoli, M. and Zuffellato. A. 2013. Housing of growing rabbits in individual, bi cellular and collective cages: Growth Performance, carcass traits and meat quality. Animal. 7(4): 627-632.

Zoltan P., Istvan, R., Nemeth, B. Matics, Z., Gerencser, Z., Nagy, I. and Szendro. Z. 2008.Effect of cage height on the welfare of growing rabbits. Applied Animal Behaviour Science 114: 284-295.

\section{How to cite this article:}

Prajapati, R.K., H.D. Chauhan, M.M. Pawar, J.P. Gupta, A.K. Srivastava, A.B. Paregi, P.D. Patel, J.V. Patel and Thakkar, N.K. 2019. Effect of Different Housing Systems on Growth Performance, Feed Consumption, Morbidity and Mortality of Broiler Rabbits. Int.J.Curr.Microbiol.App.Sci. 8(03): 2115-2121. doi: https://doi.org/10.20546/ijcmas.2019.803.253 